Extraction of a Key from the Trachea.

To the Editor:-On the evening of February i4, I 890 , Carl Blohm, aged 2 years, was brought to my office by his father, who stated that the boy had "swallowed" a key a few moments before. The patient was voiceless, dyspncea was coustant and alarming, and there was a frequent croupy cough. There was great retraction of the soft parts about the clavicles and in the inframammary regions in inspiration. It was very evident that the foreign body was somewhere in the air passages, and it seemed to me probable that it had not passed much below the larynx, as I could on no other theory account for the complete aphonia. However, neither with the finger nor with a pair of laryngeal forceps was I able to reach it through the mouth. It was plain that relief, to be of avail, must be speedy. Accordingly, after ineffectually trying a vigorous shaking with the patient inverted, I proceeded to perform tracheotomy under chloroform anæsthesia. The operation just above the isthmus of the thyroid was chosen, and in making the incision in the trachea I was so fortunate as to come directly upon the lower and smaller end of the offending key; and now came the part of the affair that seemed to me to be of peculiar interest. The key, or at least the large end of it, was so much wider than the diameter of the trachea that with the ordinary laryngeal forceps I was wholly unable to remove it from its position, as the blades of the instrument would slip off at every effort to grasp and remove the foreign body. It was only by taking a stout pair of polypus forceps that I was enabled to extract it. The key was of steel and measured 30 millimetres in length and at the widest part I 3 millimetres in width. I have not been able to find in any authority accessible to me a table of the diameters of the trachea at different ages, but I am confident that in this patient it did not exceed $7 \frac{1}{2}$ or 8 millimetres. Relief to respiration was perfect, and as soon as the little fellow regained consciousness he audibly expressed his satisfaction with the result, as $I$ held my finger over the tracheal opening to enable him to use his vocal organs. No tube was used, as I could see no indication for it, and the incision was allowed to close, which it did inside of forty-eight hours. A pretty severe bronchopneumonia came on on the second day and lasted four or five days. The patient is now practically well.

Dexter, Iowa, March I, I8go.

The McKinley TARIfF BILL has some features that will interest medical men. It allows the importation free of books and pamphlets printed in any language but the English, and of periodicals in all languages. Opium is put upon the free list.

\section{ASSOCIATION NEWS.}

\section{American Medical Association, Forty-First Annual Meeting.}

Section of Obstetrics and Diseases of Women.

The following list embraces the titles of papers that have been offered to this Section to April I.

I. "Intra-Ligamentary Cysts," by W, H. Wathen, Louisville, $\mathrm{Ky}$.

2. "Primary and Ultimate Results of Vaginal Hysterectomy for Cancer," by Charles A. L. Reed, Cincinnati, Ohio.

3. Title not announced, Rufus B. Hall, Cincinnati, Ohio.

4. "Gonorrhoeal Disease of the Uterine Appendages,"' by J. M. Baldy, Philadelphia, Pa.

5. "A Plea for Early Vaginal Hysterectomy in Cancer of the Uterus," by Franklin H. Martin, Chicago, Ill.

6. "A Retrospect of Pelvic Surgery," by Joseph Price, Philadelphia, $\mathrm{Pa}$.

7. "The Treatment in Placenta Prævia," by Aug. P. Clarke, Cambridge, Mass.

8. "Moot Points in the Doctrine of Placenta Prævia," by W. W. Jaggard, Chicago, Ill.

9. "The Treatment of Placenta Prævia, based on an Experience of Thirty-four Cases," by G. H. Balleray, Paterson, N. J.

Io. "She Supposed it was Her Change of Life," by A. Vander Veer, Albany, N. Y.

I I. Title not announced, by J. H. Kellogg, Battle Creek, Mich.

12. "A Résumé of the Ideas of Paul Portal's Pratique des Accouchments," by John Bartlett, Chicago, Ill.

13. "Psychical Results of Gynecological Operations," by I. S. Stone, Lincoln, Va.

14. "Stricture of the Urethra in Women," by Ely Van de Warker, Syracuse, N. Y.

15. Title not announced, by John B. Deaver, Philadelphia, $\mathrm{Pa}$.

16. Title not announced, by C. B. Penrose, Philadelphia, $\mathrm{Pa}$.

17. "Antiseptics in Obstetrics," by T. B. Greenby, West Point, Ky.

18. "Hyperemesis Gravidarum," by E. W. Mitchell, Cincinnati, O.

I9. "Uterus Bilocularis," by L. H. Dunning, Indianapolis, Ind.

20. "The Great Utility of Bleeding in Puerperal Convulsions," by John G. Meacham, Racine, Wis.

2I. Title not announced, by Wm. E. Ashton, Philadelphia, $\mathrm{Pa}$.

22. "A Plea for the General Adoption of the Traction Forceps," by Joseph Hoffman, Philadelphia, Pa.

23. "Surgical Treatment of Non-Pedunculated Abdominal Tumors," by Henry O. Marcy, Boston, Mass. 